\title{
Ergonomia aplicada na qualificação da ambiência do espaço de nascer
}

\author{
Cristiane Neves da Silva \\ Universidade Federal do Rio de Janeiro \\ Ministério da Saúde \\ $\triangle$ cristianensilva@gmail.com
}

Recebido em 12 de abril de 2018

Aceito em 31 de maio de 2018

\begin{abstract}
Resumo:
Este estudo tem como objetivo rever as evidências disponíveis sobre o projeto de ambientes destinados ao nascimento, mais especificamente os quartos PPP (pré- parto, parto e puerpério), a fim de identificar características relativas aos aspectos ergonomicos dos ambientes e equipamentos utilizados que possam auxiliar na diminuição do estresse materno e facilitar a fisiologia do parto. Entendendo-se a ergonomia como uma disciplina dedicada a relacionar o entendimento das interações entre os seres humanos e outros elementos ou sistemas dos ambientes e relacionando-a com as proposições relativas aos estudos de ambiência, que atentam para os aspectos subjetivos que influenciam na percepção do ambiente, busca-se identificar elementos projetuais e ergonômicos que contribuam para experiências de nascimento seguras e satisfatórias para todas as mulheres.
\end{abstract}

Palavras-chave: Ergonomia, Ambiência, Quarto PPP, Ambiente de nascer.

\section{Applied ergonomics in the qualification of the space of birth space}

\begin{abstract}
:
This study aims to review the available evidence on the design of environments for birth, specifically the PPP (prepartum, childbirth and puerperium) rooms, in order to identify characteristics related to the ergonomic aspects of the environments and equipment used that may aid in the decrease of maternal stress and facilitate the physiology of childbirth. Ergonomics is understood as a discipline dedicated to relating the understanding of the interactions between human beings and other elements or systems of environments and relating it to the propositions related to environment studies, which examine the subjective aspects that influence the perception of environment, it seeks to identify design and ergonomic elements that contribute to safe and satisfactory birth experiences for all women.
\end{abstract}

Keywords: Ergonomics, Ambience, PPP room, Birth environment.

\section{Ergonomía aplicada en la calificación del ambiente del espacio de nacer}

\section{Resumen:}

Este estudio tiene como objetivo revisar las evidencias disponibles sobre el proyecto de ambientes destinados al nacimiento, más específicamente las habitaciones PPP (pre parto, parto y puerperio), a fin de identificar características relativas a los aspectos ergonómicos de los ambientes y equipos utilizados que puedan auxiliar en la disminución del estrés materno y facilitar la fisiología del parto. Se entiende la ergonomía como una disciplina dedicada a relacionar el entendimiento de las 
interacciones entre los seres humanos y otros elementos o sistemas de los ambientes y relacionándola con las proposiciones relativas a los estudios de ambiente que atentan para los aspectos subjetivos que influyen en la percepción del conocimiento ambiente, se busca identificar elementos proyectivos y ergonómicos que contribuyan a experiencias de nacimiento seguras y satisfactorias para todas las mujeres.

Palabras clave: Ergonomía, Ambiente, Habitación PPP, Ambiente de nacimiento.

\section{INTRODUÇÃo}

O parto é um acontecimento de relevância na vida da mulher, uma vez que constitui momento único para o binômio mãe e filho. As sensações que a parturiente vivencia durante o trabalho de parto exercem grande influência sobre sua experiência. Ambientes tranquilos, seguros e com uma atmosfera calma e desprovida de pontos causadores de estresse, favorecem a evolução do trabalho de parto, pois minimizam a liberação de adrenalina, hormônio responsável por diminuir o ritmo das contrações. Diversos recursos projetuais podem ser aplicados no planejamento e no desenho dos ambientes destinados ao parto, desde a configuração espacial, controle de luminosidade e do som, até a utilização de equipamentos que auxiliem no processo de parto e na escolha de métodos não convencionais para este, propiciando às mães sensações de controle, segurança e privacidade. Estas sensações são primordiais para o andamento tranquilo do trabalho de parto até o nascimento do bebê.

O trabalho de parto é influenciado por uma série de questões de caráter físico e emocional que interferem nas sensações das mulheres, envolvendo aspectos psicológicos, físicos, sociais, econômicos e culturais. A oferta de um ambiente para o parto que possa proporcionar às parturientes a possibilidade de apropriação e controle pode também minimizar o estranhamento e a insegurança provenientes de estarem em um ambiente que não lhes é familiar e que remete a doença, do medo em relação ao parto em função de outras experiências vividas ou contadas e até mesmo das questões relativas à sua cultura e costumes familiares. É justamente o que sugere o conceito de ambiência, quando estabelece a relação do indivíduo com o ambiente, observando-o por uma ótica direcionada por todos os aspectos pessoais que lhe são pertinentes: os sentimentos, o conhecimento, a cultura, as expectativas, os medos. Os efeitos subjetivos criados por esta gama de sensações atuam sobre e, em conjunto com a percepção do ambiente, ocasionando a experiência sensível vivida pelos sujeitos a ele expostos. 
Neste contexto, a ergonomia, que é definida como uma disciplina dedicada a relacionar o entendimento das interações entre os seres humanos e outros elementos ou sistemas dos ambientes, pode ser vista como uma importante ferramenta de suporte para o projeto dos ambientes destinados ao parto. A aplicação das ferramentas de ergonomia pode auxiliar no estabelecimento de condições físicas e de equipamentos a serem utilizados em tais ambientes, de forma a favorecer a segurança, o conforto e o protagonismo da mulher em seu trabalho de parto. Um ambiente ergonomicamente pensado para atender as necessidades das parturientes lhes dará condições de atravessar com maior tranquilidade o processo do parto e influenciará em uma percepção positiva da experiência.

Se entendemos que os estudos de ergonomia buscam a interação das pessoas com o seu ambiente e pensarmos que os ambientes de atenção à saúde são locais onde esta interação é realizada em situações geralmente ligadas a sensações de insegurança estresse, expectativa, medo e dor, torna-se clara a necessidade de entender que todas as atividades e situações vivenciadas pelos pacientes, bem como sua relação com os ambientes e equipamentos disponíveis nestes ambientes devam ser objeto de análises ergonômicas.

No presente trabalho, serão levantadas características relacionadas a aspectos ergonômicos que influenciam na percepção da ambiência nos espaços destinados ao parto/nascimento, bem como da possibilidade de sua interferência negativa ou positiva no processo do parto. 0 objetivo proposto é a contribuição quanto às maneiras de projetar estes ambientes, de forma que realmente sejam adequados para propiciar, conforto, segurança, privacidade e auxiliar no bem-estar físico e mental das parturientes.

\section{ERGONOMIA E AMBIENTES DE ATENÇÃO À SAUDE}

O termo "ergonomia vem do grego ergon (trabalho) e normo (normas, regras, leis)" (FREITAS, 2012), e tem como objetivo principal estabelecer as diferenças passíveis de serem encontradas no trabalho, entre a forma real e a ideal para sua execução. Esta lacuna entre o modo como realmente o trabalho é executado e a forma ideal como deveria ser feita, baseiase em "conhecimentos de fisiologia, antropometria e biomecânica" (FREITAS, 2012), adaptando-se, desta forma, as necessidades do homem relativas ao seu ambiente de trabalho, a fim de que sejam alcançadas situações que primem pela existência de "proteção, conforto, bem-estar e eficácia nas atividades desenvolvidas" (FREITAS, 2012). Na definição da IEA - 
Associação Internacional de Ergonomia, esta "é uma disciplina científica relacionada ao entendimento das interações entre os seres humanos e outros elementos ou sistemas" (SERRANHEIRA; SOUZA E SOUZA, 2016). O estudo da ergonomia também é voltado para a aplicação de teorias, ferramentas e métodos passíveis de auxiliarem na qualificação dos projetos, com o objetivo de ampliar o bem-estar das pessoas, o desempenho e a qualidade dos processos de trabalho realizados nos ambientes.

Os estudos relativos à ergonomia consideram em seu bojo conjugar conceitos de diversas ciências relativas às atividades humanas. Tratando-se de uma área de ampliação tão extensa, torna-se necessário que os ergonomistas apliquem uma abordagem holística no estudo de suas áreas de atuação, considerando os aspectos físicos, cognitivos, sociais, organizacionais e ambientais, dentre outros, para qualificação do ambiente e dos processos de trabalho nele executados. Os campos de especialização e aplicação da ergonomia dividemse em três áreas principais: ergonomia física, ergonomia cognitiva e ergonomia organizacional.

- A ergonomia física tem relação com as características da anatomia humana e as capacidades físicas do Homem, engloba antropometria, fisiologia e biomecânica associadas à atividade física. Inclui em sua área de atuação estudos sobre a postura no trabalho, manipulação de materiais, movimentos repetitivos, distúrbios e lesões relacionados ao trabalho, a concepção dos espaços e ambientes de trabalho, além da segurança e saúde dos trabalhadores (SERRANHEIRA; SOUZA E SOUZA, 2016; ABERGO. S/D).

- A Ergonomia cognitiva é relacionada aos processos mentais, englobando a percepção, memória, raciocínio e resposta motora na medida em que estas interferem nas interações entre as pessoas e os demais elementos de um sistema/ambiente (SERRANHEIRA; SOUZA E SOUZA, 2016; ABERGO. S/D).

- A ergonomia organizacional é relacionada à otimização dos sistemas sócio técnicos, incluindo suas estruturas organizacionais, políticas e de processos. (ABERGO. S/D)

Os estudos de ergonomia visam estabelecer relações de adequação entre os aspectos humanos e os demais componentes e sistemas existentes em um ambiente, considerando todas as interfaces que possam proporcionar esta relação, positivas ou negativas. As interfaces adequadas podem funcionar de forma conjunta, integrada e eficiente, 
proporcionando sensações de conforto e segurança. Vital (2000) considera que o ser humano interage com os componentes do ambiente, equipamentos, instrumentos e mobiliário, formando interfaces sensoriais, ambientais, cognitivas e organizacionais. Ainda segundo o autor, as pessoas realizam estas interações com o ambiente de forma sistêmica, utilizando para isso seu organismo, sua mente e sua psique. O papel da ergonomia é justamente modelar tais interações, na busca da adequação dos ambientes para o desempenho das funções a serem ali exercidas, de forma confortável, eficiente e segura, atendendo às necessidades, capacidades e limitações dos seus usuários. Dentre as sensações apontadas para a percepção ambiental e a relação com o ambiente, podem ser mencionadas as seguintes: auditivas, visuais, olfativas, térmicas, táteis, energéticas e posturais.

A norma técnica que regulamenta a aplicação dos estudos de ergonomia, no Brasil, é a NR 17, basicamente voltada a estabelecer parâmetros para "adaptação das condições de trabalho às características psicofisiológicas dos trabalhadores, de modo a proporcionar um máximo de conforto, segurança e desempenho eficiente" (MTPS, 1990). Segundo Albuquerque et al (2016), ainda que os aspectos ligados à avaliação ergonômica dos ambientes sejam prioritária e especificamente desenvolvidos e direcionados para situações relacionadas ao trabalhador e sua relação com os ambientes de trabalho, nada impede que os conceitos possam ser adaptados, a fim de serem utilizados para avaliar a percepção, o conforto e a segurança de quaisquer usuários para quaisquer ambientes. No caso específico de ambientes de saúde, os estudos de ergonomia podem auxiliar na concepção de projetos que considerem a percepção e as necessidades dos pacientes, além do corpo técnico e clínico, a fim de que sejam criados ambientes que proporcionem conforto, segurança e adequação para o usuário que é atendido em tais ambientes.

Os estudos de ergonomia hospitalar têm sido dedicados, basicamente, a melhorar as condições de trabalho, conforto e segurança dos trabalhadores da área de saúde (CARDOSO e MORAES, 1998). Ely et al (2006) ressaltam que "essa questão ao destacar que as pesquisas ergonômicas na área de saúde vem dando maior ênfase aos problemas relacionados às atividades dos funcionários em detrimento das dos pacientes", fazendo com que estes se vejam impossibilitados ou encontrem dificuldades de realizar tarefas simples que poderiam ser facilitadas caso os ambientes fossem ergonomicamente pensados para o seu conforto e para isso fossem adequados. 
A utilização da ergonomia e da abordagem sistêmica por ela realizada pode qualificar não somente o trabalho assistencial realizado em edificações de assistência à saúde, mas também contribuir para a qualificação da percepção do cuidado e para o bom desempenho das funções assistenciais. Esta contribuição da ergonomia pode se dar através da utilização do design ergonômico, da composição dos ambientes às atividades a serem nele executadas e da consideração das reações humanas quando inseridas em sistemas complexos e fora de seus ambientes conhecidos e controláveis (SERRANHEIRA, SOUZA e SOUZA, 2016). A ergonomia hospitalar considera em sua gama de aspectos estudados, “a interação entre fatores pessoais como fadiga, aptidão física, idade e fatores circunstanciais e organiza o espaço da melhor forma por meio do desenvolvimento de escalas mais adequadas, mobiliário e equipamentos" (COSTA DA SILVA, 2017), aspectos que influenciam não somente o trabalho realizado, mas também o conforto e o bem estar dos pacientes dos ambientes de saúde, devendo estes serem considerados nesse âmbito dos estudos ergonômicos para tais ambientes.

\section{ERGONOMIA E AMBIÊNCIA}

Os conceitos de ergonomia e ambiência podem ser considerados como complementares, no que se refere à ideia de qualificação dos projetos e na sua adequação para proporcionar conforto, bem-estar e segurança aos usuários. A ergonomia reflete de que forma devem ser adequados os ambientes, a fim de suprir as necessidades fundamentais de seus usuários no que se refere a evidenciar as exigências e limitações dos usuários em um determinado espaço (COSTA DA SILVA, 2017). A ambiência, por sua vez, é conceituada pelo Ministério da Saúde brasileiro como uma ferramenta capaz de auxiliar a produção de projetos considerando os espaços como meios físicos, estéticos, psicológicos e estruturados, com o valor próprio dado por cada indivíduo que nele permanece ou exerce atividades (BRASIL, 2006).

O conceito de ambiência engloba o ambiente construído em conjunto com os efeitos subjetivos que este induz no comportamento dos indivíduos, considerando além da composição do espaço, a inter-relação deste com a experiência sensível que é ocasionada nos sujeitos que o habitam. O uso do termo no plural é decorrente da associação do espaço a várias ambiências, de acordo com as condições físicas, psicológicas, ambientais, temporais, culturais 
ou quaisquer outras, que possam influenciar a subjetividade dos indivíduos e mudar a percepção a cada momento ou situação (SILVA, 2018).

A utilização de ambos os conceitos, de forma a se complementarem nos projetos arquitetônicos para ambientes de saúde, efetivamente poderá contribuir para o planejamento e desenvolvimento de ambientes compatíveis com as necessidades e limitações dos usuários envolvidos nos processos de trabalho assistencial nele realizados e, mais especificamente, contribuir para que sejam estabelecidos arranjos que favoreçam o conforto e a segurança do paciente, principal ator do processo de cuidado.

Os estudos de ergonomia para ambientes de saúde, aliados aos preceitos da ambiência, conforme preconizados na Cartilha do HumanizaSus, referindo-se a elementos tais como "morfologia, cinestesia, cor, iluminação, ventilação, arte, dentre outros, podem colaborar em diferentes momentos de um projeto arquitetônico para estes ambientes" (BRASIL, 2010). Segundo Freitas (2002) podem ser considerados também os preceitos relacionados à aplicação da antropometria, voltada aos requisitos de projetos, principalmente aqueles relativos à "segurança, conforto, envoltórios de alcances físicos, postura e aplicação de formas e materiais". Consideram-se ainda os aspectos relativos aos sistemas de comunicação e informação aos usuários: "tátil, visual, auditivo, cinestésico, de vibração, códigos visuais, fatores aromáticos, morfológicos, tipos gráficos e tecnológicos". Além destes, outros elementos podem ser introduzidos na concepção dos ambientes, dependendo da atividade a ser realizada em cada um deles (FREITAS, 2002).

Vários dos aspectos mencionados, relacionados aos estudos para aplicação de ergonomia aos projetos, também se relacionam aos estudos de ambiência, identificados como atributos das ambiências, que possuem a capacidade de interferir na percepção do ambiente e servindo de base para apreensão de aspectos relativos ao meio físico a ser projetado, de forma a minimizar os efeitos negativos que possam ocasionar aos indivíduos que utilizem os espaços construídos (SILVA, 2018). A consideração de todas estas características, a serem observadas no processo projetual dos ambientes de atenção à saúde, podem contribuir para a criação de ambientes diferenciados, que possam oferecer um atendimento humanizado, seguro e confortável, contribuindo para os processos de trabalho em geral e colaborando para o processo de cura dos pacientes. 
Dentre os ambientes de atenção à saúde, um dos que merecem e necessitam de atenção diferenciada e singular, é o ambiente destinado ao parto/nascimento. Embora tenha se ampliado o conceito de cuidados centrados na mulher e no bebê durante o processo do parto, e que estas mudanças de comportamento e protagonismo tenham modificado a forma de serem pensados e organizados os serviços de maternidades e, ainda, mesmo com inúmeras normativas e recomendações sobre a humanização dos lugares de nascer, efetivamente poucas mudanças foram feitas. Deve ser considerada, ao projetarem-se ambientes destinados ao parto, a necessidade de segurança, conforto e privacidade que todas as mulheres têm em um momento tão singular. Deve-se considerar também que estas sensações, bem como a satisfação ou não pela experiência vivida, são diretamente influenciadas dentre outros fatores, pelo ambiente onde se deu o parto/nascimento, podendo marca-la como traumática ou satisfatória. (WALSH, 2007)

Costa da Silva (2017) explica que o nível de estresse experimentado pela parturiente pode interferir diretamente na percepção do parto como uma experiência segura e gratificante para a mãe. Ambientes que contenham elementos que contribuam para a sensação de segurança, conforto e privacidade, por exemplo, "minimizam o estresse materno e facilitam o trabalho de parto, contribuem para experiências de parto mais seguras e satisfatórias". O projeto de ambientes destinados ao parto deve considerar a necessidade de proporcionar às mulheres a sensação de liberdade para ir e vir, para escolher e adotar a posição que achar mais confortável para o nascimento de seu filho, para que se sintam seguras e protegidas, com a possibilidade de receberem a companhia de seus amigos e familiares, caso desejem, proporcionar privacidade e controle pessoal, de forma que a mulher possa sentir-se segura, relaxada, confortável e protagonista de seu processo de parto.

Para muitas mulheres, o ambiente de nascimento hospitalar é estranho, provoca medo e ansiedade. O medo e a ansiedade podem interromper as delicadas influências neurohormonais que interferem no trabalho de parto e no nascimento, aumentando a possibilidade de ser necessária intervenção cirúrgica (cesariana). o parto cesáreo, por sua vez, dependendo das circunstâncias em que é realizado, pode ser associado a um maior risco de uma experiência de nascimento insatisfatória, traumas e transtornos de humor pós-natal com consequências potencialmente prejudiciais para o bem-estar de mulheres, bebês e famílias. Há evidências crescentes de que os espaços de nascimento devem ser projetados para serem 
ambientes seguros, calmantes e para incentivar a minimização dos partos cirúrgicos, além de proporcionarem bons resultados clínicos e experiências positivas de parto para mulheres (JENKINSON, JOSEY e KRUSK, 2014).

Existem diversos elementos que podem ser observados através dos conceitos da ergonomia e da ambiência, a fim de serem considerados no desenho de um espaço de nascimento. A junção e utilização de tais elementos, bem como a modificação de outros, que não sejam adequados aos processos de parto, podem colaborar na configuração de ambientes que sejam pensados para favorecer as sensações positivas necessárias às mães, atender confortavelmente e de forma segura todos os passos do trabalho de parto e nascimento. Dentre tais elementos podemos considerar: elementos que propiciam privacidade, tipo de cama utilizado, possibilidade de imersão na água, existência de chuveiro e banheiro privativo, a iluminação, tipologia de janelas, incidência de ruídos, aspectos relativos à decoração, mobiliário e demais equipamentos, capacidade e espaço para se deslocar, inclusão da natureza, facilidade de acesso, aspectos olfativos, possibilidade de ter itens pessoais, possibilidade da presença de acompanhantes, considerações culturais, dentre outros (JENKINSON, JOSEY e KRUSK, 2014), sobre os quais falaremos adiante.

Dentre os modelos de ambientes projetados para o parto/nascimento, tomaremos como exemplo os quartos PPP (pré- parto/parto/puerpério), recomendados como ambientes ideais para o parto natural/normal pela maior parte das normativas do Ministério da Saúde sobre parto humanizado e comumente encontrado nos Centros de Parto Normal IntraHospitalares - CPNIH (Figura 1), também chamados de Casas de Parto. 
Figura 1: Modelo de Centro de Parto Normal

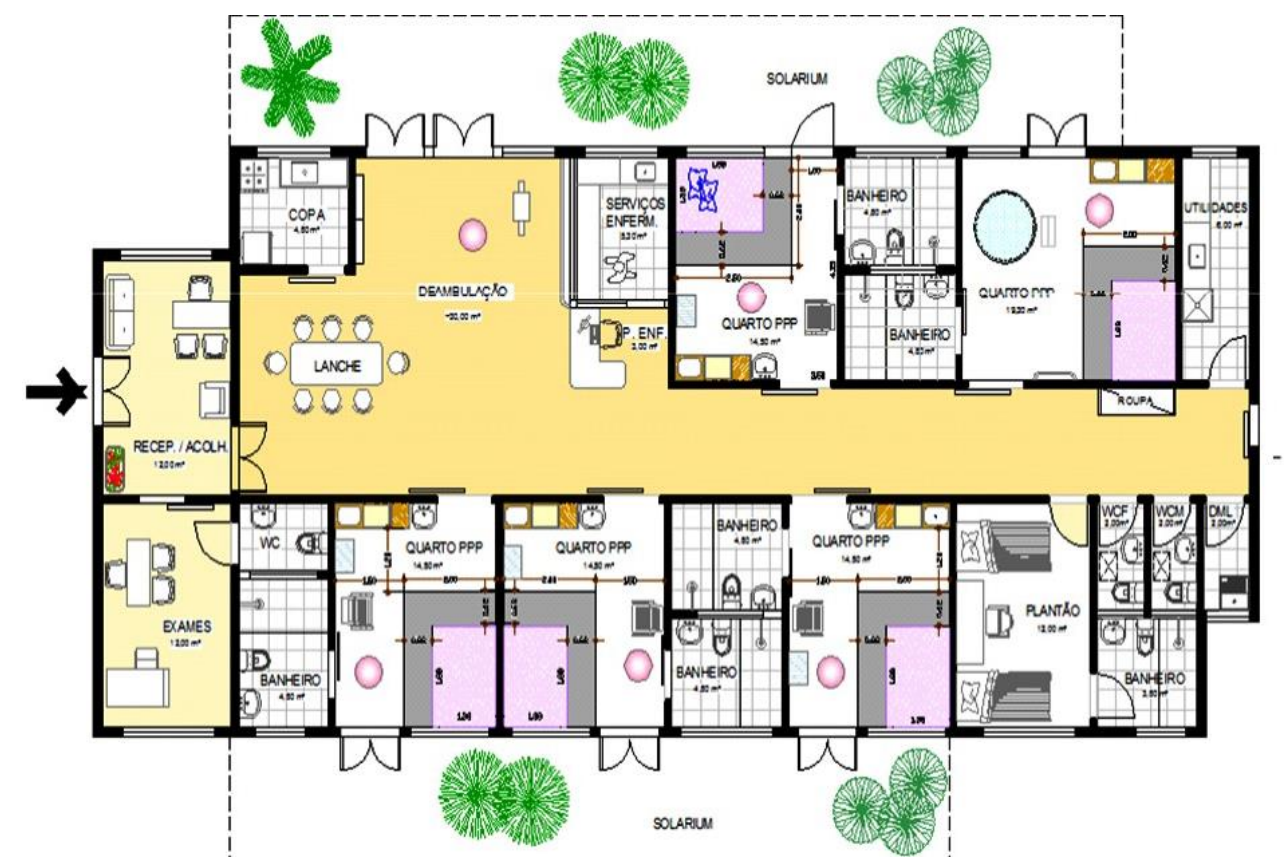

Fonte: Brasil, 2012.

"Os Centros de Parto Normal são unidades de atenção ao parto e nascimento que realizam o atendimento humanizado e de qualidade exclusivamente ao parto normal e privilegiam a privacidade, a dignidade e a autonomia da mulher ao parir em um ambiente mais acolhedor e confortável, além de contar com a presença de acompanhante de sua livre escolha." (BRASIL, 2012)

O ambiente do quarto PPP, segundo o Ministério da Saúde, deve ser projetado para proporcionar à parturiente sensações de bem-estar e segurança, através da criação de ambientes semelhantes ao lar, com aspecto familiar e diferenciado de ambientes estéreis hospitalares e de salas cirúrgicas, além de permitir a presença e a participação de acompanhante em todo o processo (BRASIL, 2012). O mobiliário fixo e os equipamentos existentes influenciam na concepção do ambiente, portanto, em geral uma abordagem minimalista para o mobiliário é a mais recomendada, dada a importância do espaço aberto na sala.

São indicados elementos como camas retráteis e cadeiras, além de equipamentos de emergência em armários acessíveis para que seja possível preservar o espaço, o que torna possível a criação de uma atmosfera menos medicalizada. 
É importante que o ambiente de parto inclua equipamentos auxiliares, tais como uma bola, o cavalo e uma corda para permitir que as mulheres escolham as ferramentas que lhes são mais úteis à medida do decorrer do trabalho de parto.

\section{AMBIÊNCIA E ERGONOMIA NOS QUARTOS PPP.}

O objetivo dos quartos PPP é a criação de um espaço no qual as mulheres são mais propensas a se sentirem seguras e relaxadas durante o parto e nascimento, em um ambiente que remeta a uma atmosfera residencial e não medicalizada. Esse ambiente é caracterizado pela privacidade e familiaridade, e proporciona à mulher uma sensação de controle pessoal $\mathrm{e}$ segurança. Alguns fatores do ambiente são fundamentais para incentivar ou diminuir estas sensações nas parturientes, podendo incentivar um trabalho de parto tranquilo e satisfatório ou ocasionar experiências estressantes e traumáticas que possam influenciar no nascimento e em gravidezes futuras.

A sensação de segurança é de suma importância para as mulheres e seus familiares, sendo então, fundamental a criação de espaços de nascimento que a estimulem, uma vez que este é um dos principais fatores por trás dos estados de relaxamento e bem-estar para as mães. A transição do espaço de casa para o hospital importa em retirar-se do território familiar para o território desconhecido do hospital. Para muitas mulheres, essa transição pode ocasionar estresse e até interromper ou atrasar o trabalho de parto. Mesmo valorizando-se, atualmente, o ambiente hospitalar como ideal e seguro para o parto, a sensação de ser observada durante todo o processo, bem como os procedimentos e exames médicos invasivos, inerentes ao próprio parto, também podem provocar respostas neuro-hormonais que dificultem o processo e o nascimento (JENKINSON, JOSEY e KRUSKE, 2014). Outros fatores que podem influenciar negativamente na percepção das mulheres sobre os ambientes, gerando insegurança e desconforto, são o aspecto estéril e impessoal comum aos hospitais, bem como a impossibilidade de se locomover e de contar com a presença de acompanhante de sua preferência. Todas as ações direcionadas a minimizar a ansiedade materna podem auxiliar a fisiologia do trabalho de parto e o próprio nascimento. 0 ambiente de nascer deve então, ser projetado com atenção nos itens primordiais que possam propiciar sensações de privacidade, segurança, controle pessoal, conforto e acolhimento. A composição física dos ambientes, bem 
como a atenção aos componentes ergonômicos neles inseridos são fundamentais para a qualificação dos locais destinados ao parto. Veremos em seguida aspectos relacionados e soluções possíveis de serem implantadas:

\section{Privacidade:}

Conforme consta em Lothian (2004), a privacidade é crucial para acalmar o neocórtex e apoiar a liberação dos hormônios necessários para o trabalho e nascimento. A não percepção da privacidade pode prejudicar a liberação da oxitocina, por exemplo, necessária para o parto e a ligação entre mãe e bebê. Isto faz com que varios mamíferos procurem privacidade para o nascimento, dando à luz em locais privados e silenciosos, longe do grupo principal. $\mathrm{O}$ ambiente físico pode dar suporte, proporcionando sensação de controle sobre a privacidade. A possibilidade de controle pessoal sobre a interação social, especialmente não familiares, é muito importante para as mulheres. Os quartos PPP utilizados nos centros de parto normal, que acomodam as mulheres desde a admissão no trabalho inicial até a alta pósnatal proporcionam esta sensação de privacidade, tanto pela possibilidade da parturiente estar em um local privado, acompanhada de seus familiares quanto por evitar deslocamentos entre ambientes durante o trabalho de parto, a menos que seja de sua vontade. São locais onde as mulheres podem vivenciar seu parto assistidas por cuidadores familiares ou amigos, que podem fornecer cuidados contínuos. As mulheres são ajudadas a se tornarem confiantes e otimistas em espaços privados, sagrados e seguros (WALSH, 2007).

Outros aspectos físicos dos ambientes, relacionados ao aprimoramento da sensação de privacidade podem ser listados, tais como: evitar a instalação de grandes vãos de janelas, a fim de não propiciar exposição. As janelas devem permitir iluminação natural, mas não a visão das atividades por pessoas externas; evitar instalaçõa de portas abrindo-se diretamente para os locais de nascimento; a instalação de cortinas secundárias ou telas devem ser usadas para criar uma barreira visível, protegendo a privacidade das mulheres parentes, mesmo quando a porta está aberta (JENKINSON, JOSEY e KRUSKE, 2014): 


\section{Posicionamento da cama:}

É extremamente comum a instalação da cama no centro da sala de parto. Normalmente este posicionamento visa facilitar o acesso dos médicos e enfermeiras às mulheres. Esta tipologia de instalação faz da cama o foco da sala contribuindo para a sensação de vigilância percebida pela parturiente, além de direcioná-la para a cama, como se esta fosse obrigatoriamente o local correto para o parto. Se considerarmos que, historicamente, o parto deitado/na cama é um fenômeno moderno, e que muitas etnias e culturas ainda escolhem o nascimento em posições verticais, torna-se necessário repensar o protagonismo da cama como mobiliário central nas salas de parto. Muitas representações históricas de mulheres dando à luz retratam estas mulheres em posição erguida ou agachada, usando cadeiras de parto (figuras $2 \mathrm{a}$ e $2 \mathrm{~b}$ ). Fisiologicamente, a posição ideal em que os seres humanos devem dar á luz é uma posição erguida ou agachada (ROSEMBERG e TREVATHAN, 2002).

Embora atualmente seja usual o parto deitado, sendo desta forma que a maior parte das mulheres dão à luz, esta posição restringe a mobilidade, os movimentos instintivos, como balanço e inclinação da pelve, que podem ajudar a facilitar a descida da cabeça do bebê e acelerar o processo de parto. Por outro lado, posições sentadas, com apoio podem aliviar as dores nas costas e incentivar contrações mais produtivas, ajudando a promover o nascimento natural / normal (JENKINSON, JOSEY e KRUSKE, 2014).

Figura 2: (a) Mulher dando à luz em uma cadeira de nascimento;(b) Cadeiras de Parto.

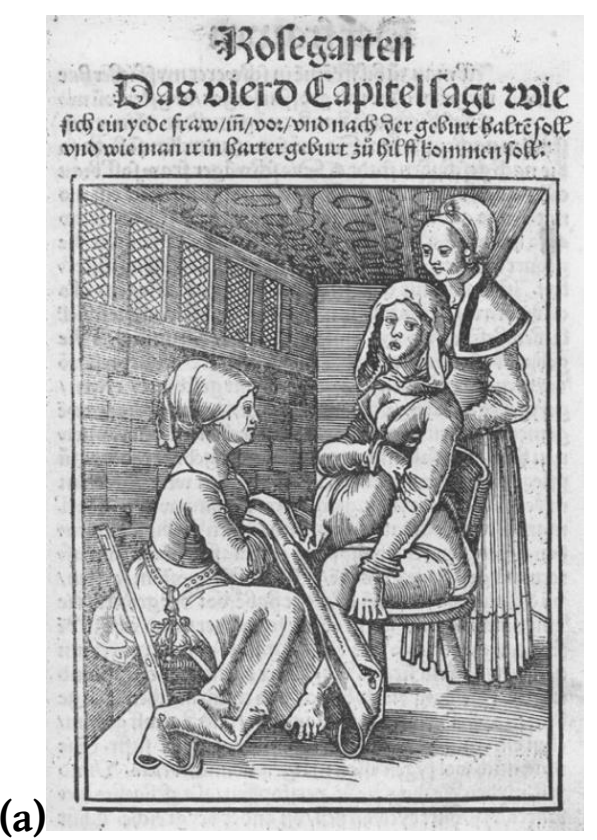

(b)

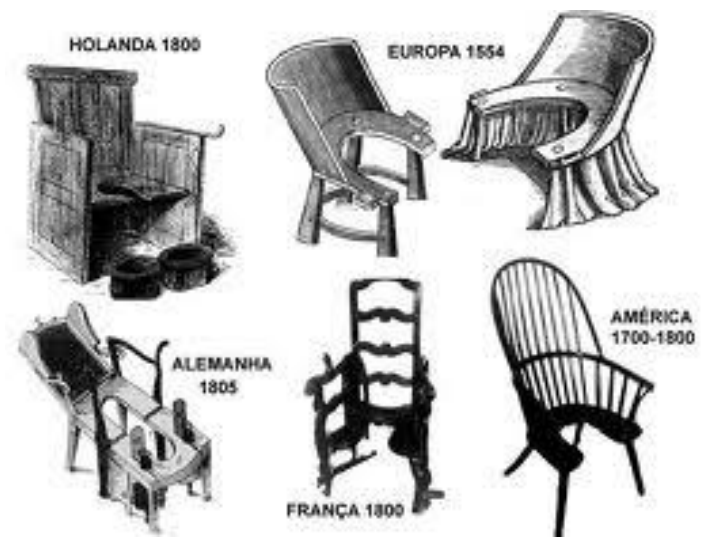

Fonte: (a) Eucharius Rößlin, Der Swangern frawen e hebamme (n) roszgarte (n) . Hagenau: Gran, um 1515. domínio público. (b) Internet. http://www.nucleobemnascer.com/content/parto-de-cocorasancestral-e-modernissimo 
Segundo a cartilha da gestante, do Ministério da Saúde, as posições de cócoras, sentada ou de joelhos (figura 3) são melhores para favorecer a saída do bebê. O canal de parto fica mais curto, a abertura da vagina fica maior e a circulação de oxigênio para o bebê é melhor (BRASIL, 2014). o fornecimento de equipamentos na sala de nascimento para apoiar a mulher a adotar e manter posições verticais também deve ser incentivado.

\section{Possibilidade de partos imersos em água.}

A utilização de uma banheira ou piscina durante o parto está associada a permitir maior mobilidade, diminuição da percepção dolorosa e contrações uterinas mais eficientes, acelerando a dilatação, a redução do uso de analgesia e da realização de cesarianas, de traumas perineais e de experiências traumáticas de parto (SCHEIDT e BRÜGGEMANN, 2016). As banheiras ou piscinas devem oferecer uma profundidade de água que permita à mãe sentar-se com esta ao nível do peito ou ajoelhar-se de forma que cubra completamente a barriga. Quantidades de água menores não são consideradas como proprias para uma imersão verdadeira e não proporcionam o efeito de flutuabilidade ou produzirá as mudanças químicas e hormonais que auxiliam o trabalho de parto (JENKINSON, JOSEY e KRUSKE, 2014) . As mulheres valorizam o acesso a estes equipamentos porque lhes proporciona sensação de privacidade e um ambiente reconfortante, relaxante e de apoio. Onde as banheiras permanentes não estiverem disponíveis pode ser avaliada a utilização de piscinas infláveis como uma alternativa (figuras $4 \mathrm{a}$ e $4 \mathrm{~b}$ ). 
Figura 3: Pôster do Ministério da Saúde ilustrando posições diferenciadas de parto.

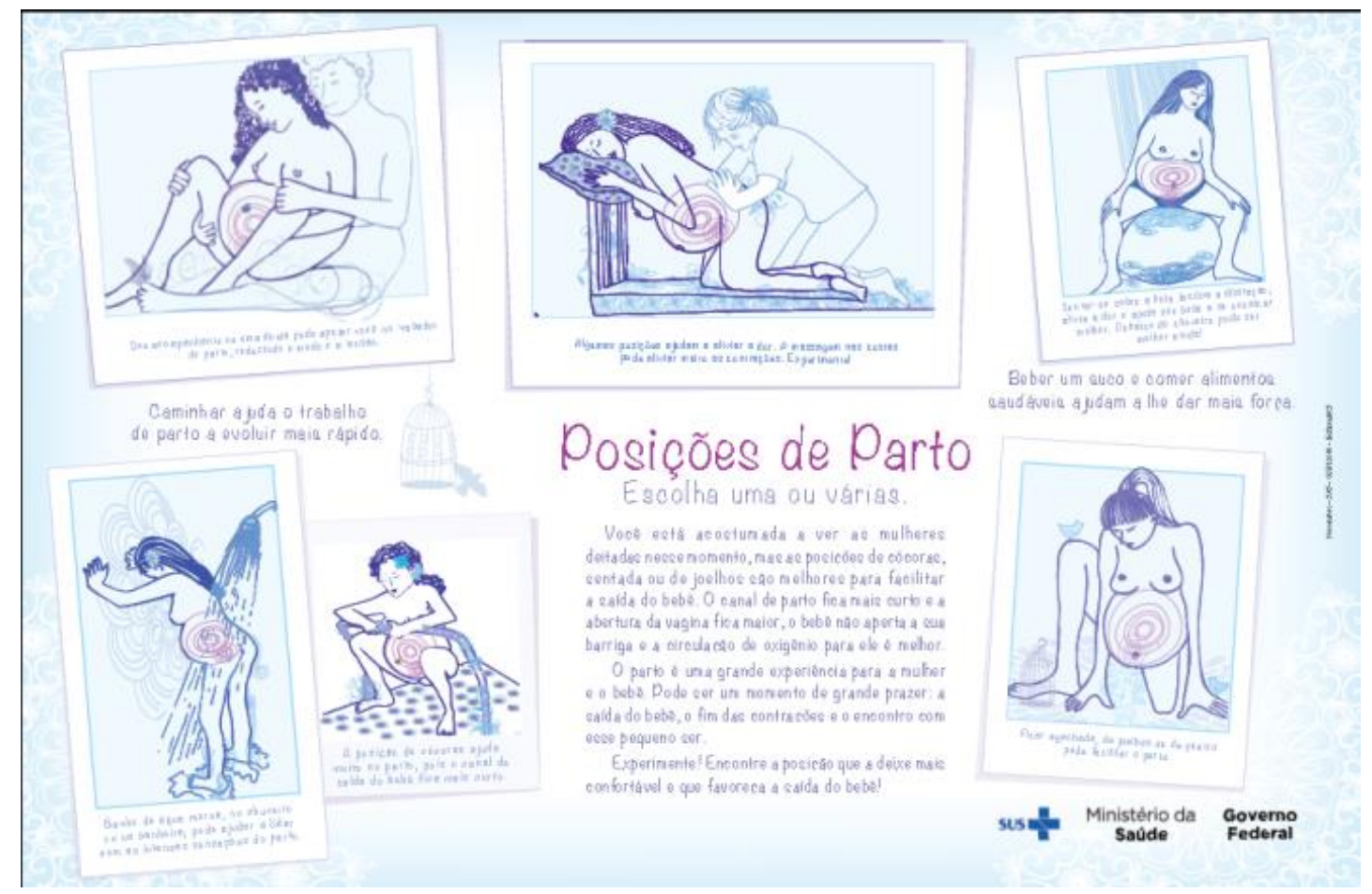

Fonte: Brasil, 2014.

\section{Banheiros individualizados, com diponibilidade de duchas.}

O acesso a um banheiro privado é positivamente avaliado pelas mulheres, sendo mencionada a utilização de duchas para o alívio da dor. Os banheiros devem possuir dimensões suficientes para acomodar duas ou mais pessoas, permitindo que o acompanhante e o pessoal técnico de enfermagem acessem a mulher. É recomendável haver um ou dois chuveiros com mangueiras para permitir que a água seja direcionada para áreas específicas, a fim de auxiliar no alivio ao desconforto e à dor. Recomenda-se a instalaçõa de barras de segurança nas paredes, a fim de proporcionar apoio às parturientes, bem como a utilização de pisos anti derrapantes. Outro aspecto sobre existencia de banheiros privativos a ser considerado, remonta justamente à questão da sensação de privacidade para a parturiente, que pode sentir-se vulnerável com a utilização de banheiros compartilhados ou com a necessidade de atravessar corredores para utilizá-los. 
Figura 4: (a) Suíte de parto com utilização de banheira localizada em um canto protegido da sala, acessível de dois lados; (b) Utilização de piscina inflável em quarto PPP

(a)

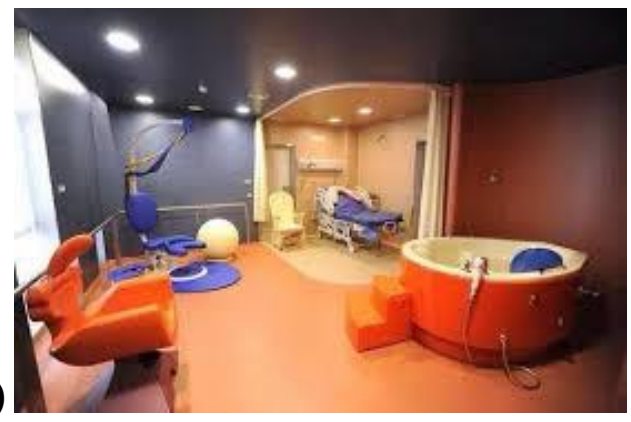

(b)

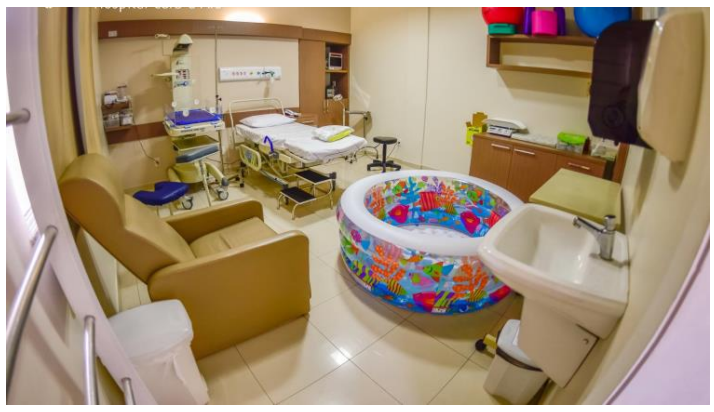

Fonte: (a) Hospital Mater dei - Belo Horizonte. - MG. (b) Internet - Hospital Maternidade São Camilo Cura Dars - Fortaleza.

\section{Iluminação}

É importante proporcionar às pacientes a possibilidade de exercerem o controle do brilho e da intensidade da luz no ambiente de nascimento. 0 projeto cuidadoso da iluminação também pode tornar o ambiente menos clínico e mais caloroso e confortável. A luz artificial e brilhante estimula o neocórtex, provocando a liberação de adrenalina e inibindo a fisiologia do parto (LOTHIAN, 2004). A luz mais brilhante pode incentivar a atividade e pouca iluminação pode criar um clima mais tranquilo e maior sensação de privacidade, além disso a iluminação pode ser usada de forma criativa e pensada para criar um ambiente relaxante. Recomenda-se que seja oferecida à mulher a possibilidade de determinar o nível de luz que a torna mais confortável durante o trabalho de parto, exceto em momentos que exigirem intervenção médica ou em caso de emergências. Outra recomendação é a de que haja iluminação alternativa às luzes de teto brilhantes, indicadas somente para realização de procedimentos médicos e que sejam instalados dispositivos que permitam ajustar a iluminação (JENKINSON, JOSEY e KRUSKE, 2014).

A cartilha da Ambiência do Ministério da Saúde preconiza os benefícios de uma iluminação adequada, que tanto pode proporcionar um ambiente aconchegante para o usuário, gerar privacidade para pacientes e trazer facilidade e segurança para o pessoal de enfermagem realizar os procedimentos assistenciais. A iluminação natural é primordial para proporcionar a noção de passagem do dia e da noite, no acompanhar da passagem do tempo, 
considerando-se que esta percepção tem influencia positiva no estado de saúde dos indivíduos(BRASIL, 2010).

\section{Ruídos}

Hospitais em todo o mundo têm níveis de ruído bem acima das diretrizes estabelecidas normativamente, incluindo os recomendados pela Organização Mundial de Saúde. O ruído ambiental contínuo parece ser inerente ao ambiente hospitalar, podendo afetar negativamente a memória, causar agitação aumentada, reduzir a tolerância à dor e aumentar o uso de medicamentos para alivio. Altos níveis de ruído ambiente são estressantes para pacientes, famíliares e funcionários e, em ambientes ruidosos, as pessoas tem menor envolvimento interpessoal, tornam-se menos cuidadosas e menos reflexivas, além de ter a cognição prejudicada: a cognição é impedida e as pessoas mostram menos perseverança (SCHWEITZER, GILPIN e FRAMPTON, 2004). Ambientes hospitalares demandam que o nível de ruído respeite o intervalo recomendado para propiciar sono adequado e o descanso para as pacientes internadas, além de não interferir nas atividades hospitalares. É comum identificar como fontes de ruído o próprio exercício das tarefas efetuadas pelos funcionários, o funcionamento de aparelhos de ar condicionado e a circulação de pessoas (ALBUQUERQUE et al, 2016). É recomendável, então, o uso de materiais absorventes de ruído, bem como ações e orientações educativas para minimizar a emissão destes. $O$ tratamento acustico nas salas de parto também pode contribuir para a privacidade das mulheres, uma vez que estas precisam se sentir confortáveis o suficiente para fazer barulho durante o trabalho de parto, sem o medo de serem ouvidas, nem devem estar preocupadas ao ouvir os sons de outras mulheres (JENKINSON, JOSEY e KRUSKE, 2014).

Por outro lado, se os efeitos negativos do ruído no ambiente hospitalar são amplamente conhecidos e entendidos, há que se considerar os efeitos terapêuticos da música, cujas pesquisas sobre a aplicação nesta área dos cuidados de saúde estão crescendo (SCHWEITZER, GILPIN e FRAMPTON, 2004). A terapia com utilização da música pode ajudar a diminuir a ansiedade e as sensações de dor nas mulheres em trabalho de parto, através da distração sensorial e através da redução da concentração da mulher em estímulos negativos. A música também pode ser utilizada para bloquear os ruídos de fundo e melhorar a sensação de privacidade da mulher (JENKINSON, JOSEY e KRUSKE, 2014). Recomenda-se então a 
utilização de materiais absorventes de ruído, tanto para conter sons dentro do espaço quanto para excluir o ruído externo. Da mesma forma recomenda-se a incorporação de equipamentos com capcidade de reprodução de musicas, cujo volume e tipo devem ser determinados pela mulher.

\section{Design de interiores, móveis e equipamentos}

É inegável o fato de que espaços planejados com cuidado relativo ao design de interiores, cor, pontos focais visuais, inclusão de obras de arte, móveis fixos e equipamentos, podem influenciar positivamente a percepção dos ambientes por todos os usuários, em especial podem ocasionar impressões positivas de conforto e reconhecimento nos pacientes, auxiliando no processo de cura. O mesmo se dá para os ambientes dedicados ao parto e ao nascimento. Em geral, é recomendada uma abordagem minimalista para o mobiliário em função da importância do espaço aberto nas salas de parto, tanto para a mobilidade da mulher quanto para o serviço médico. $O$ uso de camas retráteis ou a dissimulação de equipamentos de emergência em armários acessíveis podem preservar o espaço, além de minimizar o aspecto estéril hospitalar, criando uma atmosfera mais acolhedora. Tratando-se do design de interiores, alguns aspectos devem ser considerados com atenção:

- As Cores: O esquema de cores e os materiais utilizados podem desempenhar um papel significativo no humor e na percepção do ambiente. Recomenda-se evitar a utilização de tons de brancos e cremes, pois remetem para ambientes clinicos. Também devem ser evitadas as cores brilhantes, pois podem estimular o neocórtex. As cores ideais incluem azuis profundos, tons não-reflexivos, roxos, rosa e verdes, mas todos os tons devem ser utilizados com o intuito de criar ambientes confortáveis, acolhedores e tranquilizadores (figura 5a). Utilizando-se cores que ajudem a refletir ou absorver luz, é possível compensar sua falta ou minimizar seu excesso A correta utilização das cores pode ser um recurso extremamente útil, uma vez que a reação das pessoas a elas é profunda e intuitiva. As cores estimulam os sentidos e podem influenciar no relaxamento, no trabalho, no divertimento ou no movimento. Podem influenciar nas sensações de calor ou frio, alegria ou tristeza (BRASIL, 2010).

- Pontos focais visuais: A decoração dos quartos também pode utilizar-se de obras de arte, a fim de criar pontos focais passíveis de proporcionar uma distração positiva da dor 
durante o trabalho de parto. Também podem ser escolhidas imagens que remetam ao simbolismo, à intensidade e à beleza do nascimento (figura 5b). Aquários, sistemas de projeção de luz e janelas que proporcionem visão da natureza também podem fornecer pontos focais visuais similares.

Figura 5: (a e b) Quartos PPP (pré-parto, parto e pós-parto).

(a)

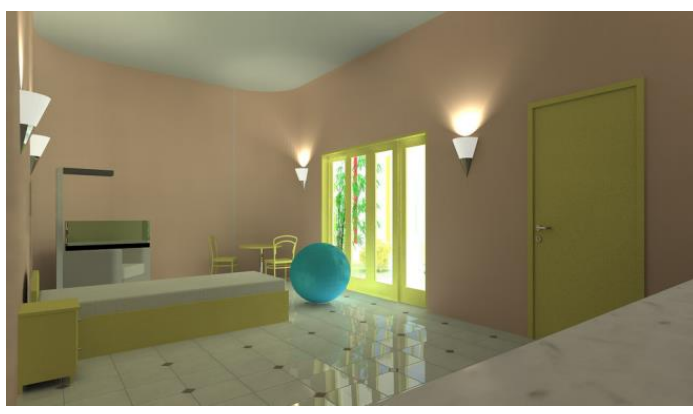

Fonte: (a) Internet. Fotógrafa Liliane Camargos. (b) Internet - internet. Hospital Regional Unimed Fortaleza (b)

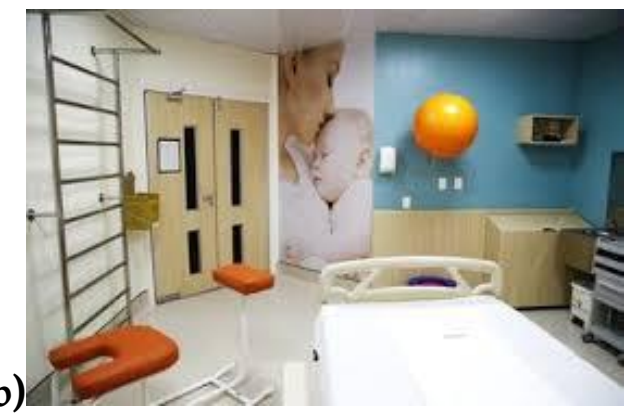
Fortaleza

- Mobiliário fixo e revestimentos: As fibras naturais, a madeira e os materiais de efeito de madeira são úteis para evitar a sensação clínica e estéril do ambiente hospitalar tradicional. $\mathrm{O}$ uso desses materiais também pode melhorar as conexões com a natureza. Todas as superfícies devem ser lisas e facilmente laváveis, respeitando as recomendações estabelecidas pela normatização referente. Outros móveis fixos podem ser usados para fornecer apoio físico às mulheres durante o parto e nascimento.

- Equipamentos: É importante que os quartos possuam equipamentos auxiliares para as mulheres durante o trabalho de parto. Estes equipamentos podem incluir uma bola, banqueta de parto, cadeira de parto vertical, cama PPP (BRASIL, 2012a), para permitir que as mulheres escolham as ferramentas que lhes são mais úteis à medida que seu trabalho de parto progride (figura 6). Diversos equipamentos podem auxiliar nas posições que facilitem a descida do bebê através do canal de parto. As bolas de parto, em particular, podem ajudar uma mulher a manter uma postura vertical e a manter sua pelve móvel. As cadeiras ou banquetas de parto são particularmente úteis para as mulheres que desejam dar à luz em uma posição de agachamento, ajudando a superar a fadiga muscular que pode acompanhar o agachamento por longos períodos. Os quartos também devem contar com mobiliário para 
conforto dos acompanhantes, dada a sua importância e permanência durante todo o trabalho de parto.

Figura 6: Exemplo de quarto PPP com cama tablado e banheira.

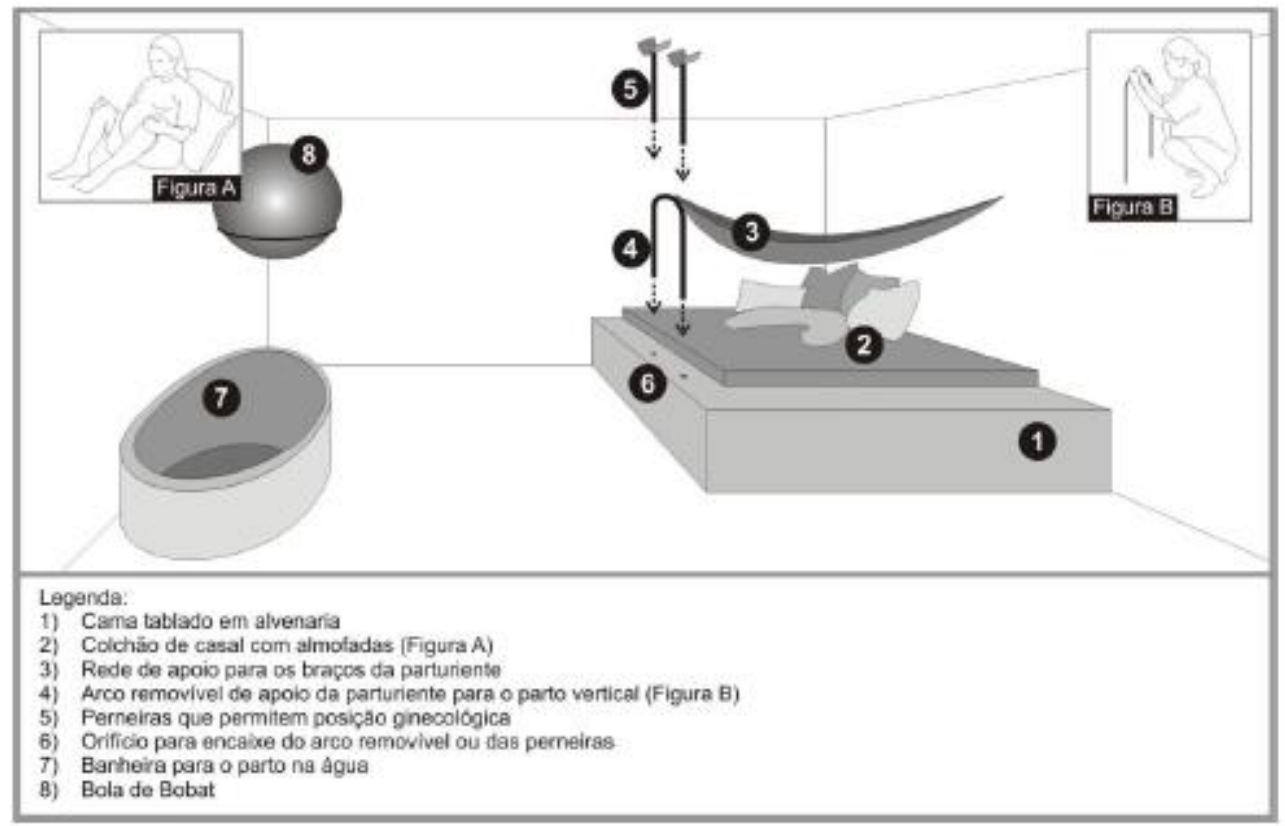

Fonte: Brasil, 2012a

- Espaço para deslocamento e deambulação: Ser capaz de circular livremente é muito importante para as mulheres durante o trabalho de parto, uma vez que a mobilidade ajuda a descida do feto através do canal de parto e encurta o trabalho de parto. Quando capazes e encorajadas a fazê-lo, as mulheres se movem livremente pelo ambiente, porém esta mobilidade pode ser influenciada pelas dimensões, pela distribuição física e a sensação de privacidade percebida na sala de parto. Recomenda-se que as salas de parto sejam suficientemente grandes para permitir que a mulher passeie e adote posições diferentes, para acomodar em conjunto seus acompanhantes e os profissionais de enfermagem; que possam acomodar uma variedade de equipamentos e opções de mobiliário; que tenham disponibilidade de equipamentos sem fio para quando houver necessidade de monitoramento contínuo da mãe e do bebê (JENKINSON, JOSEY e KRUSKE, 2014).

- Itens pessoais: Um dos fatores que influenciam a sensação de insegurança sentida pelas mulheres, ocasionando reações negativas ao ambiente hospitalar é a sua tradicional 
aparência estéril e impessoal. Se incentivadas a trazerem itens pessoais, que auxiliem na personalização do ambiente, podem superar a sensação de impessoalidade, se apossarem do ambiente e com isto estabelecerem uma sensação benéfica de controle sobre este. A sensação de vinculo, ocasionada pela presença de objetos familiares, minimiza a insegurança e, juntamente com outros aspectos já abordados em relação à manutenção do controle ambiental, consequentemente propiciam o aumento da sensação de segurança e relaxamento. A capacidade de personalizar o ambiente de nascimento, permite que as mulheres criem um "território" e lhes permita se sentir seguras. Recomenda-se então incentivar as mulheres a personalizarem o ambiente de parto, inclusive estabelecendo nos projetos espaços definidos para que exponham seus itens de importância pessoal.

- Acomodações para companhantes: Mesmo estabelecendo-se de que o foco das disposições ambientais e dos equipamentos para os ambientes de nascer sejam voltados para as mães e para o evento do parto, não se pode esquecer que estas acomodações também devem ser dimensionadas para atender com conforto aos acompanhantes. As mulheres que têm suporte contínuo durante o parto e nascimento têm melhores resultados, com taxas mais baixas de cesariana, menor uso de alívio farmacológico da dor e maior probabilidade de estar satisfeita com a experiência de nascimento. Elas também têm trabalhos de parto ligeiramente mais curtos, e seus bebês são menos propensos a ter um baixo índice de Apgar em cinco minuto (HODNET et al, 2011). Recomenda-se que os quartos sejam suficientemente grandes $\mathrm{e}$ bem mobiliados para acomodar confortavelmente os acompanhantes e que lhes seja fornecido um banheiro separado para sua utilização, nas proximidades do ambiente de nascer.

- Respeito às tradições culturais da família: Embora o parto seja um evento natural, acontecendo de forma semelhante para todas as mulheres, de qualquer etnia ou nacionalidade, variando apenas as disposições assitenciais e médicas em sua realização, existem grupos específicos cujas necessidades culturalmente específicas devem ser consideradas ao projetar ambientes de nascimento. As atitudes e crenças sobre gravidez e nascimento variam entre e dentro de culturas, devendo ser respeitadas quando da elaboração de projetos para estes ambientes. Mulheres que pertençam a grupos culturais com crenças e costumes específicos podem necessitar de que sejam observados, particularmente, alguns aspectos do ambiente de nascer: apoio ao trabalho de parto e variedade de posições para o nascimento; acesso à imersão em água para o trabalho de parto; acesso à natureza e aos 
espaços abertos, especialmente se deseja realizar cerimônias tradicionais; acomodações para acompanhantes, incluindo parentes do sexo feminino, outras mulheres de sua comunidade e às vezes, seu parceiro masculino. É recomendável, então, consultar a comunidade do local onde será construido o projeto, sobre as preferencias culturais relativas ao parto e aos ambientes a este destinados e promover e incorporar conhecimentos e práticas tradicionais dos locais e culturas para os quais serão oferecidos.

\section{CONCLUSÃO}

Conforme afirma Freitas (2012), “a ergonomia trata da relação homem-tarefa-objetosistema". Pode-se observar o exercício desta relação, em ambientes de atenção à saúde, nas interações que ocorrem entre os profissionais de medicina e enfermagem, seus usuários e os respectivos acompanhantes. Pacientes internados geralmente encontram-se limitados pelo estado físico ou de saúde, necessitando de cuidados e ambientes pensados para fornecer condições voltadas à recuperação de sua saúde. Da mesma forma, em ambientes destinados a um evento singular como o parto, as recomendações ergonômicas irão facilitar o atendimento, o cuidado e as condições para realização dos procedimentos, proporcionando conforto, privacidade, segurança e satisfação, podendo transformar-se no fator diferencial no resultado final do parto e na percepção da mulher e da família sobre a experiência vivida. 0 desenvolvimento de equipamentos pensados para funcionar de forma ergonomicamente adequada podem atuar como fatores determinantes no nível da capacidade, independência e segurança e qualidade para as parturientes e seus bebês.

A busca de literatura sobre o tema sinalizou a existência de um número significativo de publicações relativas à ergonomia na área hospitalar, mas poucas destas publicações têm o foco principal voltado para os pacientes, o que sinaliza a necessidade do investimento em estudos voltados para a avaliação ergonômica das necessidades e atividades realizadas não somente pelos funcionários, mas também por pacientes e acompanhantes, de forma que possa ser estimulada a criação de ambientes, equipamentos e sistemas mais adequados para dar suporte a todos, e não somente produtos e equipamentos voltados unicamente aos processos de trabalho em ambiente hospitalar. 
Para que todas as mulheres possam dar à luz dignamente e com toda a segurança necessária, devem ser tomadas medidas para melhorar o ambiente, garantindo o estabelecimento de padrões de qualidade para o projeto de salas usadas para trabalho de parto. Tais padrões devem garantir que as mulheres possam estar o mais confortável e relaxadas possível ao longo do trabalho de parto, que seu movimento não seja restrito, que possam controlar o aquecimento e iluminação, e que elas não se sintam expostas.

Segundo o conceito proposto pela Política Nacional de Humanização (PNH), devem-se conceber ambiências confortáveis e acolhedoras, favorecendo a privacidade e individualidade dos usuários do serviço assim como dos trabalhadores que usam o espaço. Uma experiência de nascimento segura e satisfatória depende, em grande parte, do nível de estresse experimentado pela parturiente. Embora os modelos de cuidados relativos ao parto e nascimento, tenham passado por mudanças consideráveis nos últimos anos, a maioria dos ambientes a ele destinados com aspecto e equipamentos primordialmente clínicos. Torna-se necessário, então, rever as evidências disponíveis relativas ao projeto dos ambientes de nascimento, bem como os equipamentos disponiveis, ou a necessidade de novos equipamentos, a fim de identificar características que possam minimizar o estresse materno e facilitar a fisiologia do parto. Tais estudos podem contribuir para experiências de nascimento seguras e satisfatórias para todas as mulheres, mesmo considerando-se que algumas gravidezes possam evoluir para partos que necessitem do ambiente hospitalar tradicional, muitas das mudanças ambientais podem ser feitas para melhorar a experiência de parto de todas as mulheres, independentemente do status de risco.

\section{REFERÊNCIAS BIBLIOGRÁFICAS.}

ABERGO- Associação brasileira de Ergonomia. o que é ergonomia? Disponível em: http://www.abergo.org.br/internas.php?.pg=o_que_e_ergonomia acesso em fevereiro de 2018.

ALBUQUERQUE, Y.P.; PROENÇA, R.P.C.; HECK, A.P.F.; LUZ, C.M. Ambiência de unidade de alto risco em maternidade pública: uma abordagem ergonômica. Arquivos Catarinenses de Medicina. 2016 jan.-mar; 45(1): 65-77.

BEZERRA, M. G.; CARDOSO, M. V. L. M. L. Fatores culturais que interferem nas experiências das mulheres durante o trabalho de parto e parto. Rev. Latino-Am. Enfermagem [online]. 2006, vol.14, n.3 [cited 2018-0329], pp.414-421. Disponível em: <http://www.scielo.br/scielo.php?script=sci_arttext\&pid=S0104$\underline{11692006000300016 \& \operatorname{lng}=e n \& n r m=i s 0>}$. Acesso em: janeiro de 2018.

BRASIL, Ministério do Trabalho e Previdência Social. Norma Regulamentadora NR-17 - Ergonomia. Norma Regulamentadora. Portaria MTPS n.. 3.751, de 23 de novembro de 1990. 

Brasília - DF

Agência Nacional de Vigilância sanitária - ANVISA. Resolução - RDC nº 50, de 21 de fevereiro de 2002.

Ministério da Saúde; Secretaria de Atenção à Saúde, Núcleo Técnico da Política Nacional de Humanização. Ambiência. $2^{\mathrm{a}}$ ed. Brasília: 2010

Ministério da Saúde. Orientações para elaboração de projetos: centros de parto normal (CPN); casa da gestante, bebê e puérpera (CGBP); adequação da ambiência; unidade neonatal e banco de leite humano. (Ampliação e reforma). Área Técnica de Saúde da Mulher e Área Técnica de Saúde da Criança e Aleitamento Materno. Ministério da Saúde. Brasília. DF. 2011. www.saude.gov.br/redecegonha

Ministério da Saúde. Oficina de Ambiência para o Parto e Nascimento. Rede Cegonha. Humanizasus. Política Nacional de Humanização DAPES /SAS Ministério da Saúde. Brasília. DF. 2012.

Ministério da Saúde. Orientações para Elaboração de Propostas da Rede Cegonha. Brasília. DF. 2012a (2014) Ministério da Saúde. Cartilha da Gestante. Brasília DF

CARDOSO, V.M.B.; MORAES, A. Ergonomia hospitalar: atividades de alimentação e deficiências dos equipamentos disponíveis. XVIII Encontro Nacional de Engenharia de produção e IV Congresso Internacional de Engenharia Industrial. Rio de Janeiro. 1998.

ELY, V. M. B.; CAVALCANTI, P. B.; BEGROW, A. P.; DENK, E. C. Estudo de caso de unidade de internação hospitalar com foco na percepção e comportamento dos usuários. Anais do $14^{\circ}$ Congresso Brasileiro de Ergonomia. Curitiba. 2006

FAHY, K.; FOUREUR, M.; HASTIE, C. Birth Territory and Midwifery Guardianship: Creating Birth Space. Oxford: Elsevier; 2008.

FORBES, I.; ET AL. Birthing unit design: researching new principles. Design \& Health Scientific Review, 2008. 1: p. 47-53.

FREITAS, I. B. A ergonomia nos ambientes de saúde. Revista eletrônica saúde Business, novembro de 2012. Disponível em: http://saudebusiness.com/noticias/a-ergonomia-nos-ambientes-de-saude/ Acesso em janeiro de 2018.

HADDAD E. B. Revogação da Liminar em Desfavor à Casa de Parto no Rio de Janeiro Casas de Parto no Mundo. 2004 [online]. Disponível em: http://www.casasdeparto.com.br/casasdeparto/revogacao.asp Acesso em janeiro de 2018.

HODNETT, E.; ET AL. Continuous support for women during childbirth. Cochrane Database Syst Rev, 2011. 3.

JENKINSON, B.; JOSEY, N.; KRUSKE, S. BirthSpace: An evidence-based guide to birth environment design. Queensland Centre for Mothers \& Babies, The University of Queensland. 2014.

LOTHIAN, J. Do not disturb: The importance of privacy in labor. The Journal of Perinatal Education, 2004. 13(3): p. 3-6.

MAIA, F.; FREITAS, S. Ergonomia Hospitalar e seu público alvo. 15ํㅡㄹ Ergodesign - Congresso Internacional de Ergonomia e Usabilidade de Interfaces Humano-tecnologia. UFPE - Recife - PE. junho de 2015. Disponível em: https://www.researchgate.net/profile/Fernanda_Maia3/publication/300579222_ERGONOMIA_HOSPITALAR_E SEU_PUBLICO-ALVO/links/59c178dd0f7e9b21a8265cc0/ERGONOMIA-HOSPITALAR-E-SEU-PUBLICOALVO.pdf. Acesso em janeiro de 2018.

ROSENBERG, K.; TREVATHAN, W. Birth, obstetrics and human evolution. BJOG: an International Journal of Obstetrics and Gynaecology, 2002. 109: p. 1199-1206. 
SCHEIDT, R.; BRÜGGEMANN, O. D. Parto na água em uma maternidade do setor suplementar de saúde de Santa Catarina: estudo transversal. Texto Contexto Enferm, 2016; 25(2):e02180015

SCHWEITZER, M., L. GILPIN, AND S. FRAMPTON, Healing spaces: Elements of environmental design that make an impact on health. The Journal of Alternative and Complementary Medicine, 2004. 10(1): p. S71-S83.

SERRANHEIRA, F.; SOUSA, A.; SOUSA, P. Ergonomia hospitalar e segurança do doente: mais convergências que divergências. Revista Portuguesa de Saúde Pública Volume 34, Número 3, Setembro - Dezembro 2016, Disponível em: http://www.elsevier.pt/pt/revistas/revista-portuguesa-saude-publica-323/artigo/ergonomiahospitalar-e-seguranca-do-doente-mais-convergencias-X0870902510898591. Acesso em janeiro de 2018.

SMS-SP. (2012) Secretaria Municipal de Saúde. Manual de rotinas de enfermagem do centro obstétrico. Hospital Municipal e Maternidade Escola Dr. Mário de Moraes Altenfelder Silva. Vila Nova Cachoeirinha. Coleção Protocolos HMEC 2012. 4ª EDIÇÃO. São Paulo - SP

SILVA, A.L.C. (2015). Centro de parto normal: Humanizando o Espaço. Revista Especialize On-line IPOG Goiânia - 9ª Edição nº 010 Vol.01/2015 julho/2015

SILVA, C. N. Aspectos subjetivos dos ambientes de atenção à saúde e sua relação com o ambiente construído. Arquitextos, São Paulo, ano 18, n. 212.05, Vitruvius, jan. 2018 <http://www.vitruvius.com.br/revistas/read/arquitextos/18.212/6867>.

VITAL, M.C. Introdução à Ergonomia. Apostila do Curso de Especialização em Ergonomia Contemporânea do Rio de Janeiro. Universidade do Brasil - Coppe UFRJ. 2000. Disponível em: http://www.ergonomia.ufpr.br/Introducao\%20a\%20Ergonomia\%20Vidal\%20CESERG.pdf acesso em janeiro de 2018.

WALSH, D., Evidence-based care for normal labour and birth: a guide for midwives. 2007, London: Routledge. 